Research Paper:

\title{
The Effect of Narrative Writing on Depression, Anxiety, and Stress of Pregnant Women
}

\author{
Seyedeh Tahereh Mirmolaei' ${ }^{\text {(D), Fatemeh Khalili }}{ }^{*}$ (D), Mohammad Ali Besharat ${ }^{2}$, Anoshirvan Kazemnejad ${ }^{3}$
}

1. Department of Midwifery \& Reproductive Health, School of Nursing and Midwifery, Tehran University of Medical Sciences, Tehran, Iran. 2. Department of Psychology, Faculty of Psychology and Education, University of Tehran, Tehran, Iran.

3. Department of Biostatis, Faculty of Medical Sciences, Tarbiat Modares University, Tehran, Iran

\begin{tabular}{|l|l|}
\hline $\begin{array}{l}\text { Use vour device to scan } \\
\text { and read the article online }\end{array}$ & $\begin{array}{l}\text { Whation: Mirmolaei, S. T., et al., 2020. The Effect of Narrative Writing on Depression, Anxiety, and Stress of Pregnant } \\
\text { dol'https://doi.org/10.32598/JCCNC.6.1.327.1 }\end{array}$ \\
\hline
\end{tabular}

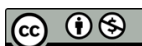

Article info:

Received: 04 Jun 2019

Accepted: 25 Nov 2019

Published: 01 Feb 2020
Keywords:

Writing, Anxiety, Depression, Stress, Pregnant women

\begin{abstract}
A B S T RA C T
Background: Pregnancy is considered a period of emotional crisis. However, attention to the mental status of a pregnant mother is often neglected by health care providers. This study was conducted to determine the effect of narrative writing on the depression, anxiety, and stress of pregnant women referring to the pregnancy care clinics in the south health centers affiliated with Tehran University of Medical Sciences in Tehran, Iran.
\end{abstract}

Methods: The research was a quasi-experimental field trial. A total of 120 eligible pregnant women referring to the south health centers of Tehran University of Medical Sciences were recruited by convenience sampling method. The health records of pregnant women were assessed at each center and the eligible subjects were identified. The sampling was performed during one week for the experimental group and during the next week for the control group. Mothers in the experimental group were asked to write a narrative about their deep thoughts and feelings, twice a week for two months according to the given instructions. The mothers in the control group received routine care. At first, both groups completed the Beck depression inventory and depression, anxiety, and stress scale 21 before the intervention. Then, at 4 and 8 weeks after the intervention, both groups just completed depression, anxiety, and stress scale 21. The obtained data were analyzed by the Mann-Whitney test, Chi-squared test, two-sample Kolmogorov-Smirnov test, and repeated measures ANOVA in SPSS V. 22. The significance level was set as 0.5 or less.

Results: Pre-intervention levels of anxiety, stress, and depression were similar in both groups. Four weeks after the intervention, the variables of depression $(\mathrm{P}=0.014)$ and anxiety $(\mathrm{P}=0.004)$ were significantly reduced in the experimental group, but no statistically significant difference was found for the stress variable in this time interval. Finally, a significant decrease was observed in all three variables as the intervention continued for 8 weeks $(\mathrm{P}<0.001)$.

Conclusion: According to the results, the narrative writing could be used as a simple and lowcost method for reducing anxiety, stress, and depression in pregnant women.

\footnotetext{
* Corresponding Author:

Fatemeh Khalili, MSc.

Address: Department of Midwifery \& Reproductive Health, School of Nursing and Midwifery, Tehran University of Medical Sciences, Tehran, Iran. Tel: +98 (937) 1655980

E-mail:fkhalili@alumnus.tums.ac.ir
} 


\section{Highlights}

- Pregnancy is associated with many psychological changes.

- Writing is one of the simple methods which reduces stress, anxiety, and depression during pregnancy.

- Expressive writing is an effective way to reduce stress, anxiety, and depression during pregnancy.

- Management of stress, anxiety, and depression of mothers is part of midwifery care.

- Midwives can recommend this simple and inexpensive method to pregnant women and provide them with better mental health.

\section{Plain Language Summary}

Pregnancy is associated with many psychological changes. Pregnant women may experience varying degrees of stress, anxiety, and depression. Lack of attention and disregard for these conditions is associated with adverse effects on the mother and fetus. Simple and non-pharmacological methods during pregnancy have drawn a lot of attention due to the lack of complications. Writing emotions on paper is a method that has been studied in various groups and is associated with positive results. In the present study, writing emotions on paper reduced stress, anxiety, and depression in pregnant women.

\section{Introduction}

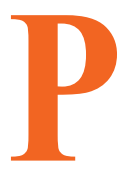

romoting health and providing a sense of wellbeing in all stages of women's life improves their quality of life (Hajmohamadi et al., 2018). Puberty, pregnancy, and menopause are critical stages of a woman's life. Although pregnancy is known as a joyful period for most women, it could be accompanied by biological, emotional, and physical challenges (Hajmohamadi et al., 2018). The results of foreign studies suggest that depression, anxiety, and low to moderate stress affect approximately $10 \%-15 \%, 25 \%-45 \%$, and $78 \%$ of women during pregnancy, respectively (Noonan et al., 2017; Fan et al,. 2016). Research suggests that severe depression, anxiety, and stress during pregnancy, both in the short and long term, are associated with detrimental effects on the health of mothers, children, and families (Signal et al., 2016). Therefore, mental health during pregnancy is a public health concern (Youliang, Zhou \& Xiang 2018).

High levels of stress during pregnancy are associated with preterm labor, and an increase in physical illnesses such as asthma, and coronary diseases in adulthood (Staneva et al., 2015; Glover 2014). The chance of low birth weight in infants of these mothers is several times higher than that of other infants (Amin-Esmaeili et al., 2011). Also, high stress in the first trimester of pregnancy increases the chance of congenital malformations (Staneva et al. 2015).
Prenatal anxiety is associated with complications such as rupture of membranes, decreased blood flow, higher incidence of growth disorders, and an increase of the risk factors of fetal death (Madhavanprabhakaran, D'Souza $\&$ Nairy 2015). Mothers with high anxiety may give birth to overactive and irritable children; these children could have sleep disorders, low birth weight, and bad eating habits (Moghadasi et al., 2016).

Depression during pregnancy is more common than postpartum depression (Baghi et al., 2013). Depressed pregnant mothers have less and irregular perinatal care and do not take health care recommendations seriously (Marcus 2009). Untreated depression in pregnancy increases the adverse consequences such as spontaneous abortion, preterm labor, intrauterine growth restriction, preeclampsia or induced hypertension pregnancy, fetal distress, and risk of cesarean section (Bowen \& Muhajarine 2006; Fishell 2010; Bonari et al., 2004).

Treatment of mental disorders in pregnancy includes a combination of medication, education, psychotherapy, and cognitive-behavioral intervention (Akbarzadeh 2012). Although pharmacologic treatment is highly successful in mental disorders, the side effects of medicines on the mother and fetus are problematic during pregnancy (Akbarzadeh 2012). It seems that non-pharmacological methods are better and safer during pregnancy. 
Narrative writing is one of the strategies that could lead to emotional modulation, anxiety reduction, and depressive symptoms decrease (Akbarzadeh 2012). Narrative writing is a way of writing by which people express their feelings and thoughts. Writing narratives for at least 15 minutes about important life experiences improves physical and mental health over three days (Krpan et al., 2013). It also prevents unpleasant emotions while strengthening problem-solving skills (Pennebaker \& Beall 1986). Indeed, writing is an easy and inexpensive way. Writing about emotions and feelings is effective in reducing the symptoms of depression, post-traumatic stress disorder, anxiety, and improving physical and psychological symptoms in patients with colorectal, breast, and prostate cancers (Pennebaker \& Seagal 1999).

It has been shown that writing about emotions and feelings for 15 to 20 minutes reduces postpartum depression and stress (Shapiro 2012). The results of the Akbari study in Iran indicated that narrative writing had reduced the stress of mothers with neonates admitted to a neonatal intensive care unit (Kadivar et al., 2017). In a study conducted on mothers with preterm infants, writing narratives about their deepest thoughts and emotions reduced the level of post-traumatic stress and symptoms of depression (Horsch et al., 2016). Similar studies support the positive impact of narrative writing on reducing symptoms of depression, stress, and anxiety in patients with multiple sclerosis (Hasanzadeh, Fallahi Khoshknab \& Norozi 2012) and asthma (Smyth et al., 1999). However, in a study on infertile couples, writing about emotions was not effective in reducing stress, anxiety, and depression (Frederiksen et al., 2017).

According to the reviews carried out in this field, despite the proven benefits of narrative writing on mental health (Krpan et al., 2013; Pennebaker \& Beall 1986; Pennebaker \& Seagal 1999; Shapiro 2012; Blasio et al., 2015; Kadivar et al., 2017; Horsch et al., 2016), there is a little research on the impact of narrative writing on stress, anxiety, and depression of pregnant women. Therefore, it seems that this area needs further research. However, since women's emotional health is the first major concern for midwives, managing these conditions is one of their responsibilities (O 'Connor et al., 2007).

Accordingly, this study aimed to determine the effect of narrative writing on depression, anxiety, and stress of pregnant women referring to the pregnancy care clinics of south health centers of Tehran University of Medical Sciences in Tehran, Iran.

\section{Materials and Methods}

This study had a quasi-experimental design with a control group. Sampling was done from late March 2017 to early October 2018 and the subjects were the pregnant women referring to the health centers of Tehran University of Medical Sciences. The inclusion criteria were 1825 year old pregnant women during their 25-28 weeks of gestational age (beginning of the third trimester, when mothers' anxiety and worry increase) (Akbarzadeh 2012), reading and writing literacy, under no medication causing depression symptoms (such as antiepileptic drugs, antihypertensive drugs, corticosteroids, digoxin, diuretics, potent sedatives, and anti-Parkinson drugs), singleton, first and wanted pregnancy, having a phone call for follow up, obtaining a score of 11-20 (mild depression) from Beck Depression Inventory (BDI),10-13 from Depression, Anxiety and Stress Scale 21 (DASS21) on the depression subscale (mild depression), 8-14 from DASS V. 21 on the anxiety subscale (mild to moderate anxiety), and 15-25 from DASS 21 on the stress subscale (mild to moderate stress), no fetal malformations during the current pregnancy, no known mental illnesses before pregnancy, no history of abortion, no chronic illnesses, no diseases causing depression (e.g. epilepsy, migraines, multiple sclerosis), not using psychotropic drugs (opium, crack, heroin), no cigarette smoking. Also, severe cases in all variables were referred to as psychological consultants.

The exclusion criteria were a change of residence, the occurrence of acute stressful events in the family during the study (such as death of relatives, spouse, infant, sudden financial problems, marital problems, and divorce), intrauterine death in the current pregnancy, delivery earlier than 37 weeks of pregnancy during the study, maternal death, unwillingness to continue study for any reason, and writing narratives less than twice a week.

The sample size was calculated as 120 (60 in each group) based on the results of a pilot study on 30 pregnant women with the same inclusion criteria as ours, a $95 \%$ confidence interval, a study power of $80 \%$, with $20 \%$ attrition per group.

The data were collected by a demographic form, BDI, and DASS 21 questionnaire. The demographic form included six questions on age, education, maternal occupation, financial status, and employment status of the subjects' wives.

The Beck Depression Inventory (BDI) includes 21 items. The items are rated on a 4-point Likert type scale from 0 to 3 . Two items of the questionnaire were associated with 
affection, 11 items with cognition, 2 items with explicit behaviors, 5 items with physical symptoms, and 1 item with interpersonal symptoms. This scale measures the different degrees of depression from mild to very severe which ranges from 0 to 63 . Scores less than 10 represents no depression, 11-20 mild depression, 2130 moderate depression, and scores more than 30 severe depression (Lovibond \& Lovibond 1995). The reliability and validity of this standard inventory have already been examined and approved in Iranian studies (Ghassemzadeh et al., 2005).

The DASS 21 questionnaire was used to measure stress, anxiety, and depression. This is the short form of the DASS42. It has three subscales of stress, anxiety, and depression (7 questions for each subscale). Scoring for each question is based on a Likert-type scale from "not at all" (0) to "very high" (3) with a range of $0-21$. The score is calculated for each subscale separately and the overall score is not calculated. The higher the score the worst the situation (Sahebi, Asghari \& Salari 2005). This questionnaire had also been validated in Iran and its internal validity for the anxiety subscale, depression subscale, and stress subscale had been reported as $0.73,0.81$, and 0.81 , respectively (Sahebi \& Asghari 2005).

After obtaining ethical approval, a permission letter was also sought from the South Health Center. The subjects were recruited by convenience sampling method from the centers and bases affiliated with the South Health Center of Tehran University of Medical Sciences. Sampling was not performed from all centers, but the health records of pregnant women were assessed at each center and the eligible mothers were considered as potential samples. Because a mother may not have visited during the week in question, complete study blindness was not possible.

After assessing the records, eligible mothers were contacted and the study was explained to them. Referral time was coordinated with the mother. To minimize data contamination, sampling was performed during one week for the intervention group, and during the next week for the control group.

After attending the center, the subjects were fully informed of the process. Mothers could withdraw from the study at any time, and this did not change their pregnancy care process. After obtaining written informed consent from eligible subjects, at first, the demographic form was given to both groups and then BDI was given to them for clinical depression screening. If they obtained a score of 11-20 (mild depression) from this questionnaire and had other inclusion criteria, they would enter the next stage. In stage two, the subjects were given the DASS
21 questionnaire and if they had mild depression based on the depression subscale and mild to moderate anxiety and stress based on the anxiety and stress subscales, they would be included in the study. Severe cases in all subscales were referred to psychological consultants. Mothers in the intervention group were instructed to write twice a week for 2 months about their deep thoughts and feelings about pregnancy, the fetus, and the issues that made them anxious and or happy during this time.

The important thing was to express their deepest thoughts and feelings on paper without being worry about correct grammar or spelling. The mothers were advised to write narratives in a quiet environment. The only rule in writing narratives was that when mothers began to write, they must continue to write for 15-20 minutes. The mothers in the control group received only routine pregnancy care per national guidelines and did not receive any intervention. Finally, 8 mothers were excluded from the intervention group ( 5 due to reluctance to stay in the study, 2 because of migration to another city, and 1 owing to intrauterine fetal death). Also, 3 mothers were excluded from the control group (because of unwillingness to stay in the study). Finally, a total of 109 pregnant mothers participated in the study ( 52 in the intervention group and 57 in the control group). At the end of the fourth and eighth weeks after the intervention, the subjects completed the DASS 21 again (Figure 1). At the end of the study, the writings were taken from the mothers and they were assured that the content will be kept confidential.

The obtained data were analyzed by the Mann-Whitney test, the Chi-squared test, two-sample KolmogorovSmirnov tests, and the repeated measures ANOVA in SPSS V. 22. To assess the effectiveness of narrative writing on depression, anxiety, and stress of the pregnant women, Tow-way repeated measures ANOVA (between-subject and within-subject mixed design) was used. Before performing this test, the statistical assumptions of the normality of the distribution of scores were evaluated using the Kolmogorov-Smirnov test. Also, the homogeneity of covariance matrices was assessed using Box's M test; homogeneity of variances was evaluated by Levene's test. Finally, the sphericity assumption was tested by Mauchly's sphericity test. Given that the above assumptions were not infringed, it was permissible to use Tow-way repeated measures ANOVA. 
Convenient sampling based on demographics, BDI and DASS21: $\mathrm{n}=$ 120

Group assignment: one week sampling for the intervention group $(n=60)$, the next week for the control group $(n=60)$

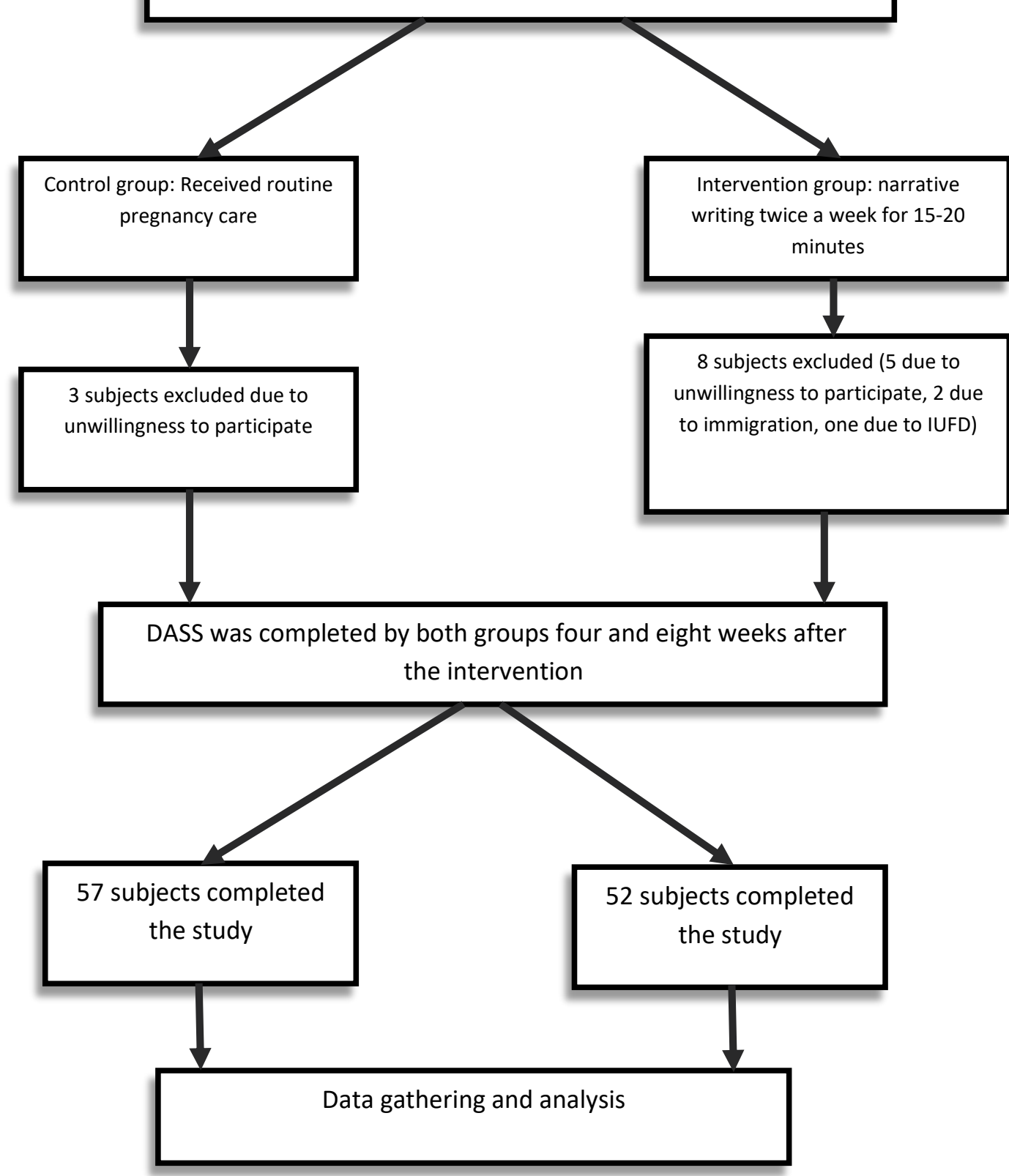

Figure 1. The flowchart of the study design 


\section{Results}

According to Table 1, the experimental and control groups were homogeneous in terms of all demographic characteristics.

Table 2 presents the mean and standard deviation of the three variables of stress, anxiety, and depression before the intervention and 4 and 8 weeks after the intervention. The two groups were initially homogeneous in terms of the severity of stress and anxiety. The level of anxiety in the experimental group decreased from 4.69 at the beginning of the study to 3.63 at the end of the fourth week $(\mathrm{P}=0.004)$ and 3.05 at the end of the eighth week $(\mathrm{P}<0.001)$, indicating a significant reduction compared with the control group. Depression also decreased from 5.25 at the beginning of the study to 4.19 at the end of the fourth week $(\mathrm{P}=0.014)$ and 3.26 at the end of the eighth week $(\mathrm{P}=0.001)$ and had a significant reduction $(\mathrm{P}<0.05)$ compared with the control group. Regarding the stress variable, although the level of stress decreased after the intervention at the end of the fourth week (from 8.84 to
7.57) and this decrease was greater than that of the control group, it was not statistically significant $(\mathrm{P}>0.05)$. Nevertheless, when the intervention continued for eight weeks, it decreased to 6.71 which indicates a significant decrease $(\mathrm{P}<0.05)$. The paired comparisons to examine the differences between the stress, anxiety, and depression scores during the intervention stages for each group are shown in Table 3.

According to the results in the experimental group, the difference between the mean scores of the pre-test phase and 4 weeks after the intervention as well as the difference between the pre-test phase and 8 weeks after the intervention were significant for all three variables. The difference between the scores obtained in the fourth and fifth weeks of the intervention was significant only for stress and anxiety and it was not significant for depression. In the control group, there was no significant difference between the mean scores of the three stages (Figures 1, 2, and 3).

Table 1. Frequency distribution of demographic characteristics in the experimental and control groups

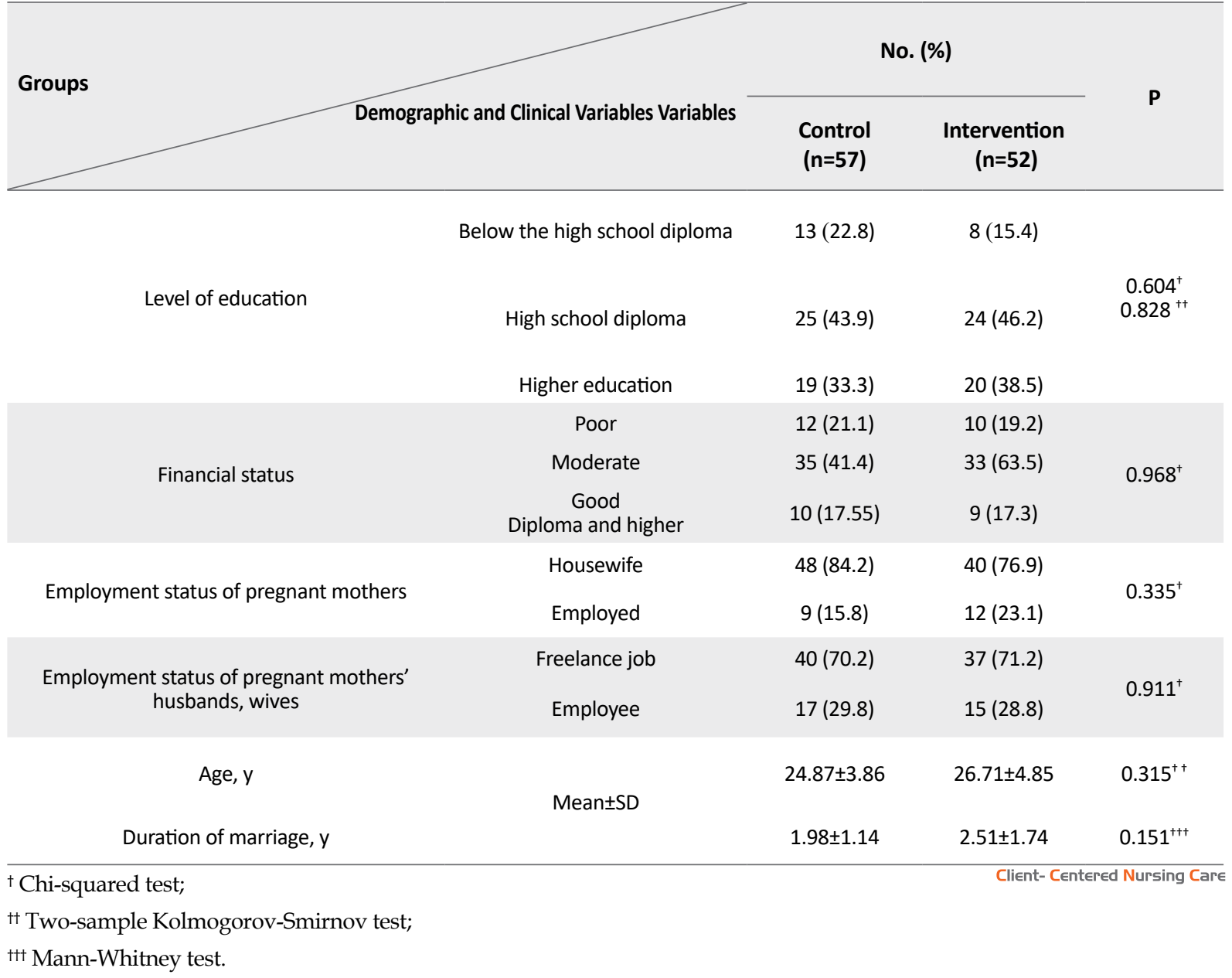


Table 2. Mean and standard deviation of stress, anxiety, and depression before the intervention, 4 and 8 weeks after the intervention

\begin{tabular}{|c|c|c|c|c|c|}
\hline \multirow{2}{*}{ Variables } & \multirow{2}{*}{ Time Point } & \multicolumn{2}{|c|}{ Mean $\pm S D$} & \multirow{2}{*}{ Test } & \multirow{2}{*}{$\mathbf{P}$} \\
\hline & & Experimental & Control & & \\
\hline \multirow{3}{*}{ Stress } & Before the intervention & $8.84 \pm 1.68$ & $8.59 \pm 0.92$ & \multirow{9}{*}{ 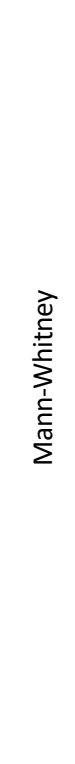 } & 0.755 \\
\hline & $\begin{array}{l}\text { Four weeks after the inter- } \\
\text { vention }\end{array}$ & $7.57 \pm 2.03$ & $8.01 \pm 1.94$ & & 0.365 \\
\hline & $\begin{array}{c}\text { Eight weeks after the inter- } \\
\text { vention }\end{array}$ & $6.71 \pm 2.29$ & $8.47 \pm 1.44$ & & $<0.001$ \\
\hline \multirow{3}{*}{ Anxiety } & Before the intervention & $4.69 \pm 1.11$ & $4.42 \pm 0.86$ & & 0.080 \\
\hline & $\begin{array}{l}\text { Four weeks after the inter- } \\
\text { vention }\end{array}$ & $3.63 \pm 1.15$ & $4.17 \pm 0.84$ & & 0.004 \\
\hline & $\begin{array}{l}\text { Eight weeks after the inter- } \\
\text { vention }\end{array}$ & $3.05 \pm 1.12$ & $4.49 \pm 1.07$ & & $<0.001$ \\
\hline \multirow{3}{*}{ Depression } & Before the intervention & $5.25 \pm 0.519$ & $5.19 \pm 0.610$ & & 0.760 \\
\hline & $\begin{array}{l}\text { Four weeks after the inter- } \\
\text { vention }\end{array}$ & $4.19 \pm 1.23$ & $4.66 \pm 1.40$ & & 0.014 \\
\hline & $\begin{array}{c}\text { Eight weeks after the inter- } \\
\text { vention }\end{array}$ & $3.26 \pm 1.35$ & $4.19 \pm 1.35$ & & 0.001 \\
\hline
\end{tabular}

Client- Centered Nursing Care

\section{Discussion}

The purpose of this study was to determine the effect of narrative writing on stress, anxiety, and depression of pregnant women. Comparison of the experimental and control groups showed that narrative writing is effective in reducing stress, anxiety, and depression.
Based on the rate of changes of the three variables, it could be concluded that the most changes have occurred over eight weeks. Continuing the intervention for eight weeks caused a further reduction of the symptoms of stress, anxiety, and depression compared to the four weeks. This reduction was greater in the stress variable. In other words, the stress variable was more affected by the intervention.

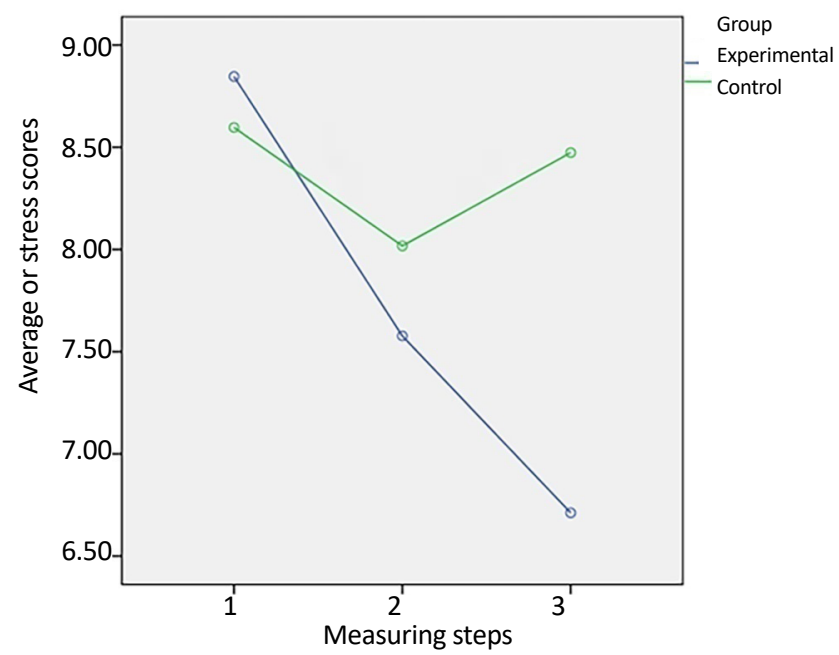

Figure 1. The process of variations of stress scores by group 
Table 3. Results of paired comparisons of stress, anxiety, and depression at different stages per each group

\begin{tabular}{|c|c|c|c|c|c|c|c|c|}
\hline \multirow{2}{*}{\multicolumn{2}{|c|}{$\begin{array}{c}\text { Variable } \\
\text { and Group }\end{array}$}} & \multirow{2}{*}{$\begin{array}{c}\text { Step } \\
\mathbf{i}\end{array}$} & \multirow{2}{*}{$\begin{array}{c}\text { Step } \\
\mathbf{j}\end{array}$} & \multirow{2}{*}{$\begin{array}{c}\text { Mean Difference } \\
\text { Between Two } \\
\text { Steps }\end{array}$} & \multirow{2}{*}{$\begin{array}{l}\text { Standard } \\
\text { Error }\end{array}$} & \multirow{2}{*}{ Sig. Level } & \multicolumn{2}{|c|}{ 95\% Confidence Interval } \\
\hline & & & & & & & Lower Limit & Upper Limit \\
\hline \multirow{6}{*}{ Stress } & \multirow{3}{*}{ Experimental group } & \multirow{2}{*}{$\mathrm{T} 1$} & $\mathrm{~T} 2$ & 1.269 & 0.308 & 0.001 & 0.521 & 2.017 \\
\hline & & & T3 & 2.135 & 0.289 & 0.001 & 1.432 & 2.837 \\
\hline & & $\mathrm{T} 2$ & T3 & 0.865 & 0.272 & 0.006 & 0.205 & 1.526 \\
\hline & \multirow{3}{*}{ Control group } & \multirow{2}{*}{$\mathrm{T} 1$} & $\mathrm{~T} 2$ & 0.579 & 0.294 & 0.154 & -0.135 & 1.293 \\
\hline & & & T3 & 0.123 & 0.276 & 1 & -0.548 & 0.794 \\
\hline & & $\mathrm{T} 2$ & T3 & -0.456 & 0.259 & 0.244 & -1.087 & 0.175 \\
\hline \multirow{6}{*}{ Anxiety } & \multirow{3}{*}{$\begin{array}{l}\text { Experimental } \\
\text { Group }\end{array}$} & \multirow{2}{*}{$\mathrm{T} 1$} & $\mathrm{~T} 2$ & 1.058 & 0.176 & 0.001 & 0.631 & 1.485 \\
\hline & & & T3 & 1.635 & 0.178 & 0.001 & 1.202 & 2.067 \\
\hline & & $\mathrm{T} 2$ & T3 & 0.577 & 0.160 & 0.001 & 0.187 & 0.967 \\
\hline & \multirow{3}{*}{ Control group } & \multirow{2}{*}{$\mathrm{T} 1$} & $\mathrm{~T} 2$ & 0.246 & 0.168 & 0.437 & -0.162 & 0.653 \\
\hline & & & T3 & -0.070 & 0.170 & 1 & -0.483 & 0.343 \\
\hline & & $\mathrm{T} 2$ & T3 & -0.316 & 0.153 & 0.125 & -0.688 & 0.057 \\
\hline \multirow{6}{*}{ Depression } & \multirow{3}{*}{ Experimental group } & \multirow{2}{*}{$\mathrm{T} 1$} & $\mathrm{~T} 2$ & 1.058 & 0.198 & 0.001 & 0.575 & 1.540 \\
\hline & & & T3 & 1.981 & 0.205 & 0.001 & 1.483 & 2.478 \\
\hline & & $\mathrm{T} 2$ & T3 & 0.923 & 0.192 & 0.001 & 0.455 & 1.391 \\
\hline & \multirow{3}{*}{ Control group } & \multirow{2}{*}{$\mathrm{T} 1$} & $\mathrm{~T} 2$ & 0.526 & 0.190 & 0.019 & 0.065 & 0.987 \\
\hline & & & T3 & 1 & 0.195 & 0.001 & 0.525 & 1.475 \\
\hline & & $\mathrm{T} 2$ & T3 & 0.474 & 0.184 & 0.034 & 0.027 & 0.921 \\
\hline
\end{tabular}

T1: Before the intervention;

Client- Centered Nursing Car

T2: Four weeks after the intervention;

T3: Eight weeks after the intervention

Although stress decreased during four weeks, this reduction was not significant and became significant as the intervention continued. It might be due to the greater stress of the subjects before the intervention compared with the other two variables.

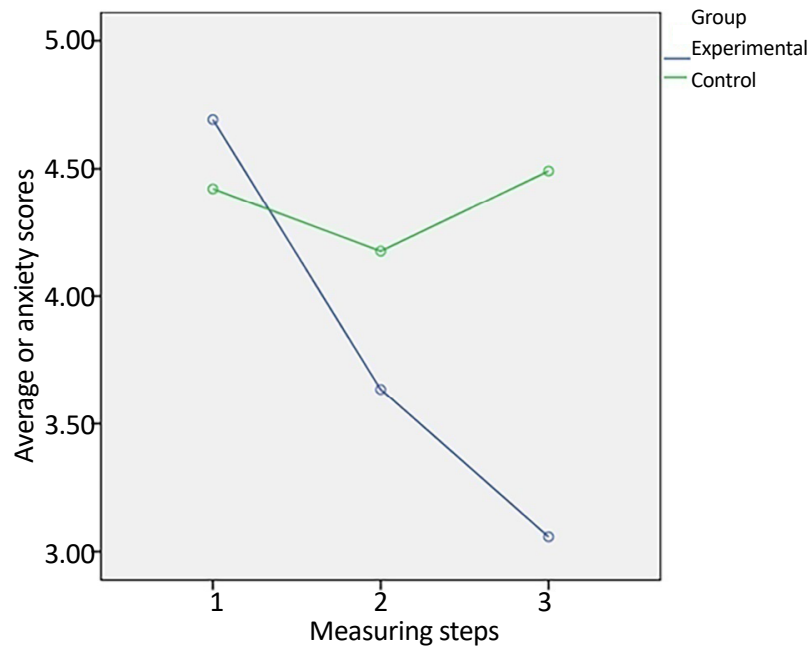

Figure 2. The process of changes in the anxiety scores by group 


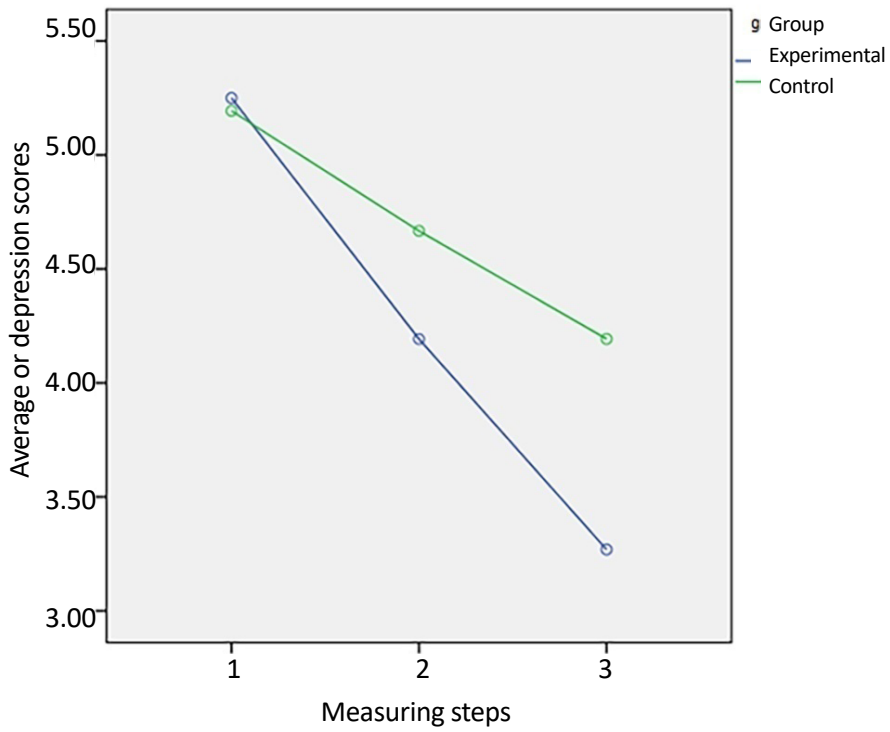

Figure 3. The process of variations in the depression scores by group

The results of this study were similar to those of Kadivar et al. (2017). In their study, the level of parental stress related to their preterm infants admitted to the neonatal intensive care units was lower in the experimental group (Kadivar et al., 2017). Another study also indicated that writing reduces post-partum stress and depression (Blasio et al., 2005). It has been also shown that narrative writing has a positive effect on improving the mental health of mothers with premature infants (Horsch et al., 2016).

The results of Frederiksen study were not consistent with ours (Frederiksen et al., 2017). This discrepancy may be due to the difference in the study population, short intervention period (3 days), and use of different questionnaires (Beck depression inventory and Beck anxiety inventory) compared to the present study.

Various studies have shown that writing about past experiences or emotional problems has an impact on mental and physical health. As an example, a study revealed that writing about emotions and feelings can improve anxiety and stress in patients with multiple sclerosis (Hasanzadeh, Fallahi Khoshknab \& Norozi 2012). Similarly, another study indicated that writing narratives about stressful experiences have reduced symptoms in patients with asthma and rheumatoid arthritis and have improved their physical condition (Smyth et al., 1999). Biological changes, childbirth factors, stressful life events, and inadequate social support during pregnancy could have a significant impact on the mental health of pregnant mothers. As such, the need for health care increases during this period. Therefore, midwives must seize the opportunity and identify women at risk to perform appropriate interventions (Noonan et al., 2017). Writing can be an effective way for patients who do not have the desire or ability to visit a psychologist or counselor. Since writing may be recognized as psychotherapy, comparing it with other therapies is reasonable. It is unclear how writing promotes health, but a complex mechanism may be involved in this process (Pennebaker \& Seagal 1999).

Despite the proven benefits of narrative writing on mental health, little research has been conducted on the impact of narrative writing on the mental health of pregnant women, and the present study is one of the few studies in this field. Therefore, this area needs further research. The prominent strength of the present study is the significant duration of interventions and samples' follow-up. However, it is not clear that the writing itself is effective, or what the person writes; therefore, it is recommended to include a third group in the next study to write just their daily activities without emotional involvement.

The present study suggested that narrative writing could be effective in the reduction of stress, anxiety, and depression of pregnant women. Midwives who are in direct contact with pregnant women can recommend this simple and inexpensive method and provide them with better mental health.

\section{Ethical Considerations}

\section{Compliance with ethical guidelines}

The study initiated with the permission of the Ethics Committee of the Faculty of Nursing and Midwifery of Tehran University of Medical Sci- 
ences (Code: 9411373005-285638) and it was registered at the Iran Registry of Clinical Trials (code: IRCT20170815035722N2). Written informed consent was obtained from the subjects. The mothers could withdraw from the study at any time, and this did not change their pregnancy care process. The subjects were assured about the confidentiality of their data.

\section{Funding}

The current study was part of the MSc. thesis of Fatemeh Khalili in the Department of Community Health Nursing, School of Nursing and Midwifery of Tehran University of Medical Sciences. Also The study was financially supported by Tehran University of Medical Sciences.

\section{Authors' contributions}

Conceptualization: Fatemeh Khalili, Seyedeh Tahereh Mirmolaei, Mohammad Ali Besharat; Methodology All authors; Investigation: Fatemeh Khalili, Seyedeh Tahereh Mirmolaei; Collecting data, writing-original draft: Fatemeh Khalili; Writing review and editing: Fatemeh Khalili, Seyedeh Tahereh Mirmolaei; Supervision: Seyedeh Tahereh Mirmolaei.

\section{Conflict of interest}

The authors declared no conflict of interest.

\section{Acknowledgments}

The authors appreciate the Faculty of Nursing and Midwifery, Vice-Chancellor for Research of Tehran University of Medical Sciences, Employees of Southern Health Centers, pregnant women involved in the study, and the library staff.

\section{References}

Akbarzadeh, M., 2012. [Mental health in pregnancy and childbirth (Persian)]. Tehran: Heydari. http://opac.nlai.ir/opac-prod/ bibliographic/2846586

Baghi, V., et al., 2013. [The relationship between antenatal depression and sleep apnea (Persian)]. The Iranian Journal of Obstetrics, Gynecology and Infertility, 16(52), pp. 18-24. http:// eprints.mums.ac.ir/4802/

Bonari, L., et al., 2004. Risks of untreated depression during pregnancy. Canadian Family Physician, 50, pp. 37-9. [PMID] [PMCID]
Bowen, A., \& Muhajarine, N., 2006. Antenatal depression. Canadian Nurse, 102(9), pp. 26-30. [PMID]

Blasio, P. D., et al., 2005. The Effects of expressive writing on postpartum depression and posttraumatic stress symptoms. Psychological Reports, 117(3), pp. 856-82. [DOI:10.2466/02.13. PR0.117c29z3] [PMID]

Fan, F., et al., 2016. Effects of maternal anxiety and depression during pregnancy in Chinese women on children's heart rate and blood pressure response to stress. Journal of Human $\mathrm{Hy}$ pertension, 30(3), pp. 171-6. [DOI:10.1038/jhh.2015.64] [PMID]

Fishell, A., 2010. Depression and anxiety in pregnancy. Journal of Population Therapeutics and Clinical Pharmacology, 17(3), pp. e363-9. [PMID]

Frederiksen, Y, et al., 2017. The effect of expressive writing intervention for infertile couples: A randomized controlled trial Human Reproduction, 32(2), pp. 391-402. [DOI:10.1093/humrep/dew320] [PMID]

Ghassemzadeh, H., et al., 2005. Psychometric properties of a Persian-language version of the beck depression inventory - second edition: BDI-II-PERSIAN. Depression and Anxiety, 21(4), pp. 185-92. [DOI:10.1002/da.20070] [PMID]

Glover, V., 2014. Maternal depression, anxiety and stress during pregnancy and child outcome: What needs to be done. Best Practice E Research Clinical Obstetrics \& Gynaecology, 28(1), pp. 25-35. [DOI:10.1016/j.bpobgyn.2013.08.017] [PMID]

Hajmohamadi, N., et al., 2018. The "Cooperative-Supportive" intervention for improving mental health status among pregnant women. Journal of Caring Sciences, 7(2), pp. 101-6. [DOI:10.15171/jcs.2018.016] [PMID] [PMCID]

Hasanzadeh, P., Fallahi Khoshknab, M., \& Norozi, K., 2012. [Impacts of journaling on anxiety and stress in multiple sclerosis patients (Persian)]. Complementary Medicine Journal of Faculty of Nursing \& Midwifery, 2(2), pp. 183-93. http:// cmja.arakmu ac.ir/article-1-21-en.html

Horsch, A., et al., 2016. Improving maternal mental health following preterm birth using an expressive writing intervention: A randomized controlled trial. Child Psychiatry \& Human Development, 47(5), pp. 780-91. [DOI:10.1007/s10578-015-0611-6] [PMID]

Kadivar, M., et al., 2017. Evaluation of the effect of narrative writing on the stress sources of the parents of preterm neonates admitted to the NICU. The Journal of Maternal-Fetal $\mathcal{E}$ Neonatal Medicine, 30(13), pp. 1616-20. [DOI:10.1080/1476705 8.2016.1219995] [PMID]

Krpan, K. M., et al., 2013. An everyday activity as a treatment for depression: The benefits of expressive writing for people diagnosed with major depressive disorder. Journal of Affective Disorders, 150(3), pp. 1148-51. [DOI:10.1016/j.jad.2013.05.065] [PMID] [PMCID]

Lovibond, P. F., \& Lovibond, S. H., 1995. The structure of negative emotional states: Comparison of the Depression Anxiety Stress Scales (DASS) with the Beck Depression and Anxiety Inventories. Behaviour Research and Therapy, 33(3), pp. 335-43. [DOI:10.1016/0005-7967(94)00075-U]

Madhavanprabhakaran, G. K., D'Souza, M. S., \& Nairy, K. S., 2015. Prevalence of pregnancy anxiety and associated factors. International Journal of Africa Nursing Sciences, 3, pp. 1-7. [DOI:10.1016/j.ijans.2015.06.002] 
Marcus, S. M., 2009. Depression during pregnancy: Rates, risks and consequences. Canadian Journal of Clinical Pharmacology, 16(1), pp. e15-22. [PMID]

Moghadasi, M., et al., 2016. [The effect of supportive counseling on reducing the anxiety of women at risk of preterm birth (Persian)]. The Journal of Urmia Nursing and Midwifery Faculty, 14(2), pp. 151-8. http://unmf.umsu.ac.ir/article-1-2553-en. $\mathrm{html}$

Noonan, M., et al., 2017. Midwives' perceptions and experiences of caring for women who experience perinatal mental health problems: An integrative review. Midwifery, 45, pp. 56-71. [DOI:10.1016/j.midw.2016.12.010] [PMID]

O ‘Connor, T. G., et al., 2007. Prenatal mood disturbance predicts sleep problems in infancy and toddlerhood. Early Human Development, 83(7), pp. 451-8. [DOI:10.1016/j.earlhumdev.2006.08.006] [PMID] [PMCID]

Pennebaker, J. W., \& Beall, S. K., 1986. Confronting a traumatic event: Toward an understanding of inhibition and disease. Journal of Abnormal Psychology, 95(3), pp. 274-81. [DOI:10.1037/0021-843X.95.3.274] [PMID]

Pennebaker, J. W., \& Seagal, J. D., 1999. Forming a story: The health benefits of narrative. Journal of Clinical Psychology, 55(10), pp. 1243-54. [DOI:10.1002/(SICI)10974679(199910)55:103.0.CO;2-N] [PMID]

Sahebi, A., Asghari, M. J., \& Salari, R. S., 2005. [Validation of depression, anxiety and stress scale (DASS-21) for an Iranian population (Persian)]. Journal of Iranian Psychology, 1(4), pp. 299-310. http://jip.azad.ac.ir/article_512443.html

Shapiro, J., 2012. Narrative medicine and narrative writing. Family Medicine, 44(5), pp. 309-11. [PMID]

Signal, T. L., et al., 2017. The prevalence of symptoms of depression and anxiety, and the level of life stress and worry in New Zealand Māori and non-Māori women in late pregnancy. Australian and New Zealand Journal of Psychiatry, 51(2), pp. 168-76. [DOI:10.1177/0004867415622406] [PMID]

Smyth, J. M., et al., 1999. Effects of writing about stressful experiences on symptom reduction in patients with asthma or rheumatoid arthritis: A randomized trial. Journal of the American Medical Association, 281(14), pp. 1304-9 [DOI:10.1001/ jama.281.14.1304] [PMID]

Staneva, A., et al., 2015. The effects of maternal depression, anxiety, and perceived stress during pregnancy on preterm birth: A systematic review. Women and Birth, 28(3), pp. 179-93. [DOI:10.1016/j.wombi.2015.02.003] [PMID]

Youliang, O. U, Y., Zhou, Y., \& Xiang P., 2018. Effect of obstetric fine nursing on pain during natural childbirth and postpartum recovery. Iranian Journal of Public Health, 47(11), 1703-8. [PMID] [PMCID] 
This Page Intentionally Left Blank 